- Change policies and practices within countries to support health in workplaces

- An increase in occupational health and medicine organisation's profile amongst the public, and influential groups such as employers, unions and policy makers

- Increased awareness of the reality of workers' health and the specific problems faced by particular industries or workplaces.

Participants will be asked to consider their objectives, and identify key institutions and individuals relevant to the interests and activities of occupational health and medicine. Core advocacy concepts such as issue identification and analysis; power mapping; lobbying and influencing; working in alliances and campaigning and public outreach will be stated, as part of an advocacy strategy.

Reference will be made to the document, 'the value of occupational health', produced by the Society of Occupational Medicine and publicly available at www.som.org.uk. An international version of this document is in process of being produced and will aim to be made available for this session. A draft Advocacy Toolkit, produced by the International Occupational Medicine Society Collaborative will also be available.

Advocacy Occupational Health

\section{CASE STUDIES IN MOVING RESEARCH INTO PRACTICE: SEPARATING REALITY FROM DESIRE}

${ }^{1}$ Max R Lum*, ${ }^{2}$ Seong-Kyu Kang*. ' National Institute for Occupational Safety and Health; ${ }^{2}$ Gachon University, Gil Medical Centre, Incheon, Rep of Korea

\subsection{6/oemed-2018-ICOHabstracts. 188}

Aim of special session New advances in moving research into practice has greatly assisted in delivering our OSH information and making an impact. Increasingly OSH researchers and their organisations must make a concerted effort to better translate the findings of their research to their stakeholders, partners, workers, employers and especially to the general public to assist in making better health decisions. This session will address the key factors and relevant case studies that help us understand the factors that improve systemic planning as well as what strategies assist communicating with hard to reach audiences, the general public, key organisations, health professionals, policy makers and assess the impact and relevance of the information and the messages we are delivering. Sustainability of the activities will be addressed.

${ }^{1}$ W. Kent Anger, ${ }^{2}$ Garrett Burnett, ${ }^{3}$ Jani Rotusalainen, ${ }^{4,5}$ Van Eerd, ${ }^{6}$ Inger Schaumburg

${ }^{1}$ Oregon Health and Science Centre, Portland, Oregon

${ }^{2}$ National Institute for Occupational Safety and Health, Cincinnati, $\mathrm{OH}$ USA

${ }^{3}$ Cochrane Work, Finnish Institute of Occupational Health, Kuopio, Finland

${ }^{4} 1$ nstitute for Work and Health, Toronto, Canada

${ }^{5}$ University of Waterloo, Canada

${ }^{6}$ National Research Centre for the Working Environment, Copenhagen, Denmark

\section{5a TOOLKITS: THE KEY TO SCALABLE INTERVENTIONS AND EFFECTIVE DISSEMINATION}

W Anger, A Rameshbabu. Oregon Health and Science University, Portland, OR USA

10.1136/oemed-2018-ICOHabstracts.189
Introduction While workplace intervention research is prevalent and fairly well funded, there remains a gap in the uptake of such interventions within practice realms after the completion of the research project. A review of the intervention research in Total Worker Health (TWH) was used to estimate the degree to which interventions were disseminated or available for dissemination in the area of employee safety, health and well-being. Among other considerations, a key strategy for effective dissemination of interventions depends on tailoring the intervention protocol and methods to a form that is widely useable.

Methods The Oregon Healthy Workforce Centre (OHWC), a US National Institute for Occupational Safety and Health Centre of Excellence in Total Worker Health (TWH), developed and evaluated TWH intervention programs that integrated safety, health, and well-being. The interventions produced positive and statistically significant changes in safety, health, and well-being. To facilitate the effective transfer of these interventions into practice, we set out to systematically translate each research-focused intervention for real-world practice.

Result Each intervention was converted into a ready-to-use, self-guided 'toolkit' designed so that practitioners could independently and feasibly implement within their workplace, thus making them scalable. The final product included videos and documents explaining the goals and strategies of the toolkit, its various components, and necessary instructions for use. In addition to ease of use, the toolkit components range from low- to no-cost to enhance their reach and distribution. Marketing materials were developed to stimulate the dissemination of the toolkits.

Discussion Toolkits from the OHWC have been made available on a university website with the marketing materials being distributed widely. Given that research interventions are often confined within academic constraints, the concept of the self-contained toolkit makes the intervention scalable, thus overcoming a key barrier of translation of sound TWH research efforts into practice.

\section{5b A GOOD IDEA THAT FAILED: A TECHNOLOGY TRANSFER CASE STUDY}

G Burnett. National Institute for Occupational Safety and Health, Cincinnati, OH USA

\subsection{6/oemed-2018-ICOHabstracts. 190}

Introduction Advances in technology and innovations in intellectual property are natural outputs of labs performing occupational safety and health research. Many of these new ideas and technologies have the potential to evolve into products or practices that can be adopted in the workplace. Yet practical innovations with a strong market potential routinely fail despite their promise.

Methods The National Institute for Occupational Safety and Health (NIOSH) analysed a variety of workplace safety and health technologies that were never transferred beyond the lab. We mapped their development and considered points at which an alternative process may have led to a more successful outcome. To inform our analysis, we applied product adoption literature from marketing and business strategy fields.

Result We found that most prototypes developed by research organisations were created with laboratory usage in mind. 
Others were created with input from potential customers or partners, but many aspects of their design, production, and marketing would have benefited had third parties taken over these roles.

Discussion By better understanding the nature of an innovation and by framing that innovation in a business-rather than a laboratory-context, research organisations are more likely to successfully commercialise their technologies. By establishing stronger positions within industry value chains, research organisations are able to form partnerships and better leverage their own core competencies.

\section{$1675 c$ A HANDY DECISION AID FOR TRANSLATING RESEARCH FINDINGS INTO A VISUAL FORMAT TO AID DISSEMINATION}

Jani Routsalainen, Jos Verbeck. Cochrane Work, Finnish Institute of Occupational Health, Kuopio, Finland

\subsection{6/oemed-2018-ICOHabstracts.191}

Introduction Cochrane is a global scientific network that produces evidence on the effectiveness of all manner of interventions to improve health. The organisation also promotes the use of this evidence in decision making both at the personal as well as the population level. Over the past few years Cochrane has developed a Knowledge Translation (KT) strategy to better ensure that the evidence it produces has real effects in real life by making people healthier and safer. One exciting and constantly growing area in KT is visualisation because pictures grab people's attention and they are easy to share via social media.

Methods Using an open, iterative, trial-and-error approach, we have developed a decision tree (a particular kind of flowchart) to help anyone interested in turning Cochrane review results - published as text, numbers and statistical graphs - into more easily understandable visual formats.

Result The decision tree will be publically available in all its development versions via www.visuallycochrane.net.

Discussion Visualisations of Cochrane review results can range from the relatively simple form of adding a photograph to a tweet at one end of the spectrum to the production of sizeable infographics or even videos at the other. There are factors inherent to the obtained review results, such as direction and magnitude of effect and the quality of the evidence, as well the general context within which they apply that can be operationalized into a rough algorithm. Even though the tool is developed especially with Cochrane reviews in mind, there is no reason to assume it would not apply equally to other kinds of research findings and their dissemination within the OHS realm. The tool will be presented in Dublin in its current form to elicit feedback to develop it further.

\section{5d KNOWLEDGE TRANSFER AND EXCHANGE IN WORK AND HEALTH: REACHING WORKPLACE AUDIENCES}

\footnotetext{
1,2D Van Eerd. 'Institute for Work and Health, Toronto, Canada; ${ }^{2}$ University of Waterloo, Waterloo, Canada
}

\subsection{6/oemed-2018-ICOHabstracts. 192}

Introduction Workplace injury and illness can be burdensome for individual workers, workplaces, medical systems, insurance systems and society as a whole. The notion of research to practice is important in work and health research. Konwledge transfer and exchange (KTE) is the practice of generation synthesis and dissemination of research. The objective of this presentation is to synthesise the literature describing KTE activities relevant to workplace health and safety programs and interventions.

Methods A comprehensive review of the literature was completed. Search strategies developed using terms for knowledge transfer and occupational health and safety were run in six electronic databases. (Medline, Embase, Eric, Social sciences, Web of Science, and Business Source Premier). References of relevant documents and hand-searching complimented the search. Documents that described a KTE approach for workplaces were reviewed. KTE approach data were extracted and synthesised according to a framework by Lavis (2003) (What, To whom, By Whom, How, and With what effect) as well as conceptual guidance.

Results Literature searchers revealed 34 documents that described 23 different KTE approaches designed to reach workplaces. The KTE approaches addressed workplace and intermediary audiences. KTE methods and outcomes varied greatly according to the context. However, there were common elements including targeting workers as a key audience involving researchers in dissemination and using multi-dissemination methods. Dissemination method consistently included direct interaction but also often featured printed materials. Many KTE approaches were guided by conceptual frameworks. However, no single conceptual framework was predominant.

Conclusion Common elements related to audience, activities and impact were found in the literature that can help to guide future KTE approaches. Including workers as an audience and researchers as disseminators in a multi-faceted approach along with in-person meetings and printed material are important aspects of KTE for work and health. Conceptual guidance was content dependent.

\section{$1675 \mathrm{e}$ THE NEW DANISH FRAMEWORK FOR KNOWLEDGE TRANSLATION AND EXCHANGE (KTE)}

I Schaumburg. National Research Centre for the Working Environment, Copenhagen, Denmark

\subsection{6/oemed-2018-ICOHabstracts.193}

Introduction The NRCWE's is a government research institute. This makes relevance and user-orientation basic terms when it comes to the institute's working environment research and research dissemination. However, our experiences shows that there may be a gap between research results and the workplaces' ability to put research into practice. For different reasons, research results are not always put into practice, and the causes to the problem cannot be limited to be a communication problem only. The NRCWE is thus conducting research with the purpose to increase our knowledge of implementation possibilities and to develop new operational methods. Systematic involvement of stakeholders and target groups during the whole research process and development of collaboration, networks and partnerships in dissemination of research are central elements. The NRCWE's ambition is to develop and implement Knowledge Transfer and Exchange (KTE) in its overall strategy 2018-2021. 